\title{
Experimental determination of suboptimal parameters for energy-efficient control of an induction motor
}

\author{
Valentina S. Goun, Aleksandr S. Anikin, Aleksey A. Bakin \\ South Ural State University (NRU), Russian Federation
}

\begin{tabular}{l}
\hline \hline Article Info \\
\hline Article history: \\
Received Feb 3, 2020 \\
Revised Apr 26, 2020 \\
Accepted Jul 9, 2020 \\
\hline
\end{tabular}

\section{Keywords:}

Induction motor

Polynomial dependencies

Power factor

Proportional control law

Thyristo voltage converter

\begin{abstract}
The article presents the results of experimental studies of the automatic speed control system (ASCS) of an induction motor (IM). Preliminary experimental studies have shown that the stator current minimum (power factor) is a suboptimal criterion. Optimal in terms of control is the rated power factor. Tests of IM with a thyristor voltage converter (TVC), as a power source, were conducted on an installation created at the department. A mathematical model of ASCS IM corresponding to the experimental setup has been developed. To determine the main functional dependences of IM, such as stator voltage, stator current, power factor, torque on the shaft, a program for approximating experimental data by polynomials was developed. Using the developed mathematical model, the regulatory characteristic of IM that was optimal from an energy point of view was obtained. The necessary indicators of IM and TVC are determined (thyristor control angle, stator voltage, stator current) to change existing settings in order to save electric energy. The results of experimental studies are presented, the graph shows an optimized version of the form of the regulatory characteristic according to the criterion of minimum electric energy consumption.
\end{abstract}

This is an open access article under the CC BY-SA license.

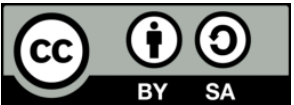

\section{Corresponding Author:}

Aleksandr S. Anikin,

Departement of Theoretical fundamentals of electrical engineering,

South Ural State University,

76, Lenin prospekt, Chelyabinsk, Russia. 454080

Email: anikinas@susu.ru

\section{INTRODUCTION}

In modern conditions, the problem of energy saving during operation of asynchronous electric drives with variable load is becoming especially acute $[1,2]$. To solve this problem, it is necessary to provide energy-efficient operation of an induction motor (IM) in the entire range of changes in the load moment. For this, it is necessary to determine such parameters of the motor at which it will develop the required moment with a minimum consumption of electric energy. For example, a number of studies in this area [3-6] show that when underloading due to a decrease in the amplitude of the supply voltage of the MI at a constant frequency, a minimum of losses can be obtained, i.e. provide energy-saving operation and reduce motor heating. The authors indicate that the mode of "minimum stator current" is close in energy indicators to the mode of minimum losses in the IM, not taking into account the value of the power factor.

The scientific team led by N. F. Ilyinsky (Moscow Power Engineering Institute) [7, 8] showed that due to the regulation of the amplitude of the supply voltage of constant frequency, when for technological reasons, for a significant part of the operating cycle, the load moment is $2 \ldots 3$ times less than the rated It is possible to save up to $15 \%$ of energy consumed, reduce motor heating by $1.5 \ldots 2$ times, increase power factor at low load by $30 \%$. Therefore, by lowering the voltage across the stator windings to 0.7 Un for the 
half load mode or to $0.4 \mathrm{Un}$ for the idle mode, it is possible to ensure energy-efficient operation of the motor, and hence the whole electric drive. However, the experimental results and real practical recommendations were not presented by the authors.

As you know, electrical energy in the IM is transmitted by a magnetic field. The amplitude of the magnetic flux mainly depends on the amplitude of the voltage across the stator windings and is practically independent of the material and dimensions of the core. Thus, any mode of operation of the IM can be represented as nominal for some abstract motor of the corresponding power. For any nominal mode, the generalized energy efficiency parameter is the power factor, which is determined by the best ratio of current and voltage. The purpose of this work is to demonstrate by practical example that the maximum power factor is the most optimal criterion for ensuring energy-efficient operation of the IM in any mode. To achieve this goal, a mathematical model was created, preliminary calculations of the speed control loop of the IM with a thyristor voltage converter (TVC) were carried out, and the optimal control characteristic of the IM was theoretically built.

\section{PROBLEM DEFINITION}

In most cases, IM works in two modes: close to nominal, and close to idle (low load mode). The goal of this work is to create an inexpensive and easy-to-manage ASCS, as well as a linearized model of IM drive for determining feedback coefficients and stability studies A suitable area of application of IM with a minimum of power consumption are the mechanisms working with variable load, in the "idling - rated load" mode. To solve this problem, in the case of small and medium-sized motors, it is necessary to create an easyto-use, but accurate mathematical model "Proportional regulator-IM- load". The mathematical model is based on the static and dynamic characteristics of ASCS. The mathematical model of IM with TVC for the study of steady-state and transient processes is based on polynomial dependencies on the mode parameters [9-12]. The model is based on experimental data of IM of various powers. As an example of the implementation of such a system, a second-order system with feedbacks on the rotational frequency and stator current is presented. It was practically established that in such a system, with the calculated coefficients of the static speed controller and feedbacks, the stability is within the engineering requirements.

\section{THEORETICAL RESEACHES}

The application of TVC is used to control the voltage at a constant frequency. In the study of proportional control systems with a predetermined control characteristic, that is, with a standard proportional voltage regulator, the main problem is to determine the functions of the reference signal, the transfer function of the TVC, and the operating parameters of IM.

The development and improvement of ASCS for the rotation of IM with TVC is expedient to be performed by calculation and experimentation. The mathematical description of ASCS can be very diverse. In calculating studies of IM transient processes, systems of linear differential equations describing the elements of ASCS are widely used. It should be noted that the characteristic transient processes are the processes of instantaneous increasing and decreasing of load. They differ insignificantly (8-10\%) of the values of the rotation speed of the IM from its values in the steady state. In the study of such modes, the use of linear models of ASCS gives a fairly good agreement between the calculated and experimental data. A good result is a description of the characteristics of ASCS elements by polynomial dependencies based on experimental data [13-17]. A structural diagram that satisfactorily describes the transient processes in IM when it is fed from TVC is shown in Figure 1, where TCV - thyristor converter, SS - speed sensor, CS current sensor, PPCC - pulse-phase control circuit.

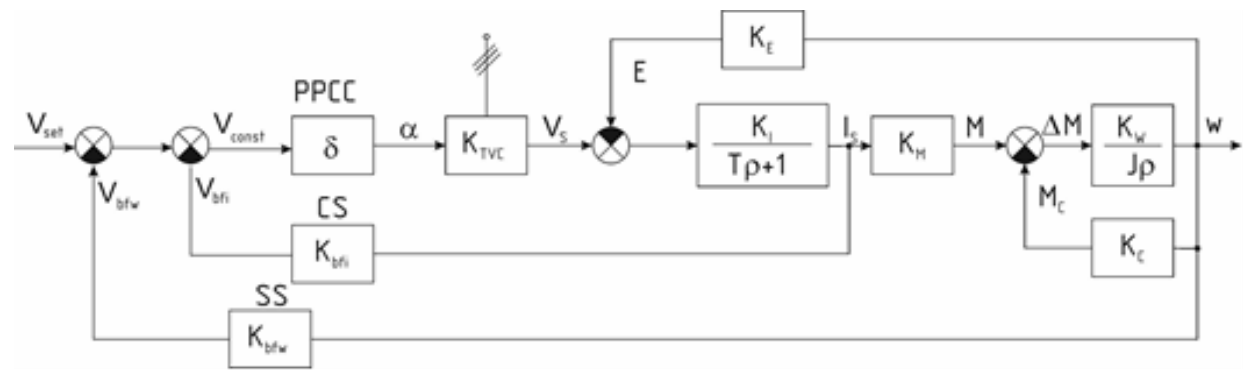

Figure 1. Block diagram of the ASCS IM

Int J Pow Elec \& Dri Syst, Vol. 11, No. 4, December 2020 : 2173 - 2182 
The moment of resistance of the consumer was described by the expression:

$$
\mathrm{Mc}=\mathrm{kc} \times \mathrm{n}
$$

where $\mathrm{kc}$ is the proportionality factor of the consumer setting. An evaluation of the effect of reduced voltage on the dynamic parameters of IM was carried out using the developed mathematical model of ASCS IM. In the developed model the differential equations of the most significant elements of the ASCS are used in the following form [18]:

$$
\begin{aligned}
& (\mathrm{TIM} \times \mathrm{p}+1) \times \mathrm{M}=\mathrm{k} \times(\mathrm{w} 0-\mathrm{w}), \\
& \mathrm{M}-\mathrm{Mc}=\mathrm{p} \times \mathrm{w} / \mathrm{Js},
\end{aligned}
$$

where Js is the total moment of inertia of the IM with the drive; TIM - the electromagnetic time constant of $\mathrm{IM} ; \mathrm{k}$ is the rigidity modulus of the linearized mechanical characteristic; $\mathrm{w} 0$-synchronous rotational speed; $\mathrm{w}$ is the current rotational speed.

The first equation describes the linear mechanical characteristic of the IM in the working zone, where the slip s varies from 0 to sкp. The second equation is a rigidly modified mechanical link.

Based on the experimental data, the following assumptions were made:

- The main functional dependencies were described by second-order polynomials;

- It is assumed that the valves are single-operation thyristors, in which only switching can be controlled. The thyristor is turned off instantly by software when the condition for the current drop that is currently flowing through the thyristor to zero is met;

- When calculating the thyristor is considered as an ideal valve, the switching time of which can be neglected ( $(\mathrm{tp}<0.006 \mathrm{sec})$.

- We also neglect the voltage drop on the open thyristor ( $\mathrm{V}<1.5 \%$ of the maximum switching voltage). Consequently, the TVC can be represented as an amplifying link;

- $\quad$ IM is an aperiodic link of the second order [18];

- The proposed quality criterion-power factor-is also written in the form of a second-order polynomial depending on the IM parameters and load.

The sensors of the mode parameters are described by algebraic equations:

Vbfw $=\mathrm{kbfw} \times \mathrm{w}, \mathrm{Vbfi}=\mathrm{kbfi} \times \mathrm{Is}$

Without allowance for discreteness in signal extraction [2]. The role of the static speed controller is performed by the ASCS with a transmission factor $\delta$ (slope of the sawtooth), which is numerically equal to the reciprocal of the gain. The values of $\delta$ and, kbfw, kbfi are chosen by the results of analysis and synthesis, proceeding from the provision of specified dynamic properties of the circuit [15-19]. Differential equations describing the control loop for the frequency of rotation of the IM in the transient process (Midle - Mnom, Mnom - Midle) take the form:

$$
\begin{aligned}
& (\mathrm{L} 1 / \mathrm{R} 1) \times \mathrm{p} \mathrm{J}=(\text { Vset }-\mathrm{kbfi} \times \mathrm{Js}-\mathrm{kbfw} \times \mathrm{w}-\mathrm{ke} \times \mathrm{w}) / \mathrm{R} 1 \\
& \mathrm{p} \times \mathrm{w} / \mathrm{Js}=\mathrm{M}-\mathrm{Mc},
\end{aligned}
$$

where L1 is the total inductance of the stator winding; R1-active resistance of the stator winding; Vset-speed reference signal; ke-coefficient, taking into account the internal parasitic feedback on the frequency of rotation; Js is the total moment of inertia of the IM and load. Since the system is a second-order system, two feedbacks are introduced to ensure stability: current and speed: kbfi and kbfw are the current and rotational feedback coefficients, respectively. Using the theory of modal control, studies were conducted on the stability of closed loop operation and the parameters $\delta=1, \mathrm{kbfi}=2, \mathrm{kbfw}=1$ [20-25] were chosen. The purpose of ASCS is the optimal functioning of the controlled system in the presence of an external load, as a rule, random. The values of the parameters of IM and TVC entering the right-hand sides of the equations, in accordance with the recommendations of $[19,26,27]$, were determined in the form of the above-mentioned functional dependences. The value of the reference signal according to the speed of rotation Vset is chosen according to the experimental characteristic, starting from the condition: minimum idle current and small loads (maximum power factor) while maintaining stable operation of the IM. Then the control signal will look like: 
Vcs $=$ Vset - Vbfw-Vbfi

The control signal Ves is compared in ASCS with a sawtooth signal as shown in Figure 2. According to the test results, under certain assumptions TVC within the performance (Midle - Mnom) of IM, the operating range of the angle $\alpha$ of regulation of the Impulse-Phase Control System (IPCS) within 60-90 degrees. The voltage at the output of TVC as a function of a is defined as:

$$
\mathrm{Vd}=160-1,067 \mathrm{a}
$$

The dependence $V_{d}(a)$, (where $V_{d}=V_{s}$ ), constructed from the experimental data, is shown in Figure 3. The functional dependencies of the experimental data of the motor under investigation were described by polynomial second-order dependences. To determine the function of setting the signal $V_{\text {set }}(n)$ and the quality criterion-the power factor, linear dependences were constructed.

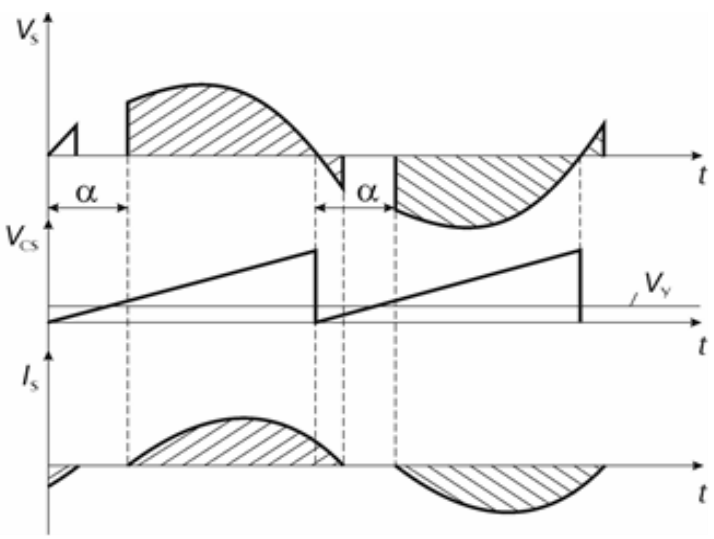

Figure 2. Timing diagrams of open loop operation

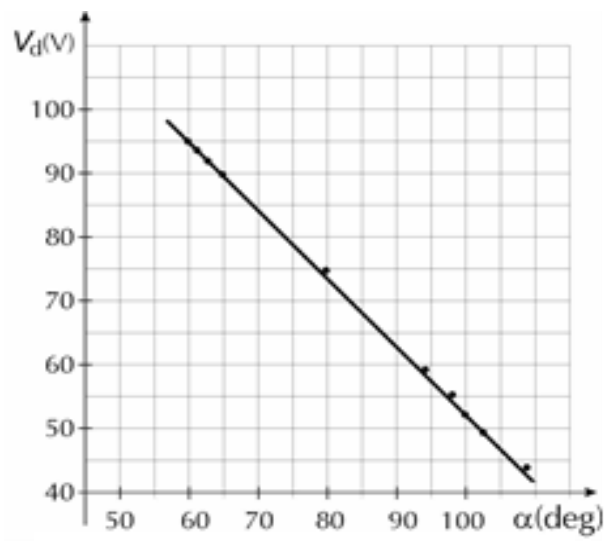

Figure 3. The voltage at the output of TVC depending on the angle of control of IPCS

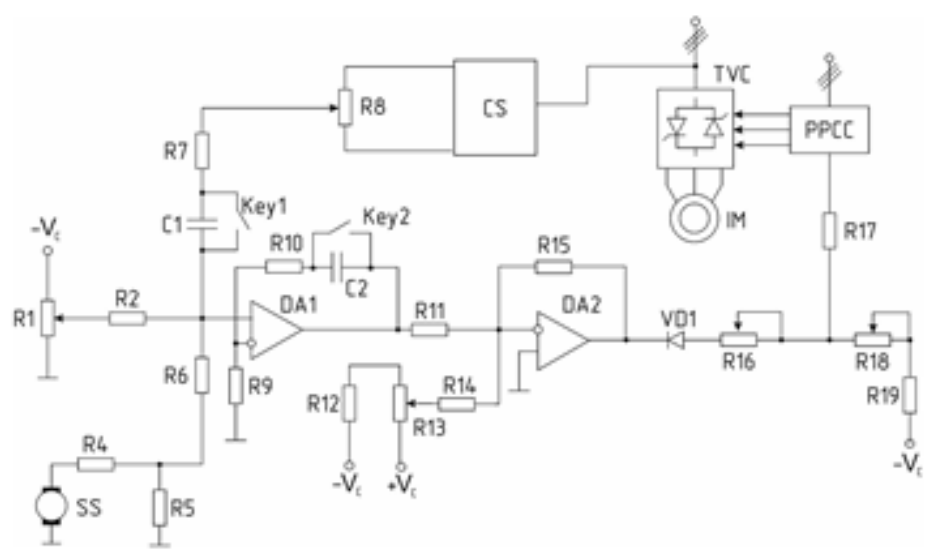

Figure 4. Diagram of the experimental setup

\section{PRACTICAL RESEARCH}

The experimental setup created in the training laboratory made it possible to build and analyze the static characteristics of the motor 4A80B6 in idle and low load modes. Static characteristics are given in Table 1, Figure 5: idle and low load modes for optimal settings are considered. Is-stator phase current, $\cos \varphi$-power factor, $V s$-phase stator voltage, $n$-rotor speed, $P_{1}$-power drawn from the supply network, $P_{2}-$ useful power, $M$-torque developed by the motor; $a$-thyristor control angle. The work of the motor under reduced voltage is stable.

An optimal control characteristic was obtained by the criterion of minimum current while maintaining effective power. On Figure 6: 1-is a natural electromechanical characteristic; 2-idle response 
when changing the reference signal without driving the load on the shaft; characteristic 3-corresponds to the idle characteristic with a drive on the shaft; 4-corresponds to a characteristic with an motor load moment equal to 0.2 of the nominal; characteristic 5-corresponds to the moment of motor load equal to 0.4 of the nominal; characteristic 6-corresponds to the moment of motor load equal to 0.6 of the nominal; 7corresponds to the moment of motor load equal to 0.8 of the nominal.

Table 1. Test 4A80B6: $P_{\text {nom }}=1,1 \mathrm{~kW}, n_{\text {nom }}=920 \mathrm{~min}^{-1}$, idling and low load modes with reduced voltage according to the criterion of the minimum stator current (maximum power factor)

\begin{tabular}{cccccccc}
\hline$M(\mathrm{Nm})$ & $n\left(\mathrm{~min}^{-1}\right)$ & $V_{s}(\mathrm{~V})$ & $I_{s}(\mathrm{~A})$ & $a(\mathrm{grad})$ & $\cos \varphi$ & $P_{l}(\mathrm{~W})$ \\
\hline $\mathbf{0 , 1 5}$ & 975 & 44 & 0,52 & 108 & 0,65 & 23 \\
$\mathbf{0 , 5 5}$ & 970 & 49,8 & 0,7 & 102,5 & 0,78 & 71 \\
$\mathbf{0 , 7 5}$ & 967,5 & 51,1 & 0,8 & 101,2 & 0,78 & 97 \\
$\mathbf{0 , 8}$ & 965 & 52,5 & 0,88 & 100 & 0,77 & 105 \\
$\mathbf{1 , 2 5}$ & 960 & 55,2 & 1,03 & 97,5 & 0,78 & 161 \\
$\mathbf{1 , 4 1}$ & 957,5 & 56,6 & 1,13 & 96,25 & 0,77 & 184 \\
$\mathbf{1 , 5 8}$ & 955 & 58 & 1,18 & 95 & 0,77 & 204 \\
$\mathbf{1 , 8 8}$ & 950 & 58,5 & 1,3 & 94,5 & 0,76 & 245 \\
$\mathbf{2 , 0}$ & 947,5 & 58,8 & 1,38 & 94,25 & 0,75 & 126 \\
$\mathbf{2 , 2 3}$ & 945 & 59,1 & 1,45 & 94 & 0,74 & 264 \\
$\mathbf{2 , 3 9}$ & 942,5 & 66,3 & 1,5 & 87,5 & 0,75 & 268 \\
$\mathbf{2 , 5 5}$ & 940 & 74,5 & 1,55 & 80 & 0,75 & 315 \\
$\mathbf{2 , 8 3}$ & 935 & 90,3 & 1,68 & 65 & 0,74 & 293 \\
$\mathbf{3 , 1 8}$ & 930 & 92 & 1,83 & 63,33 & 0,72 & 331 \\
$\mathbf{3 , 5 3}$ & 925 & 93,6 & 1,95 & 61,67 & 0,72 & 221 \\
$\mathbf{3 , 9}$ & 920 & 95,3 & 2,1 & 60 & 0,70 & 256 \\
\end{tabular}

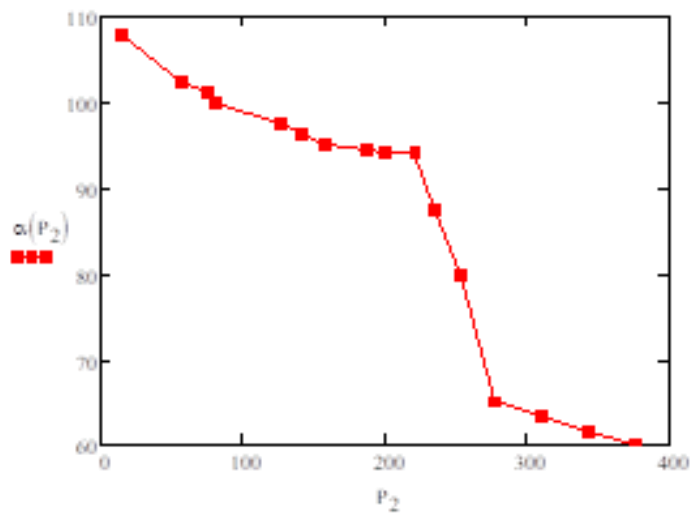

(a)

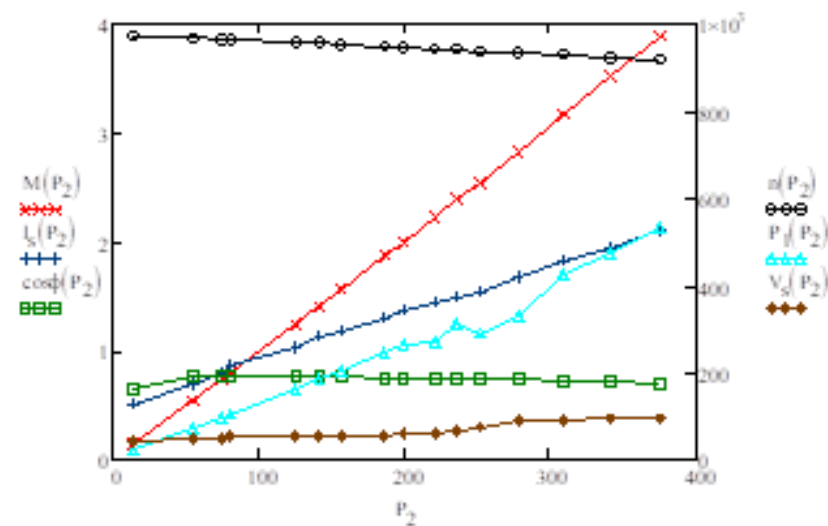

(b)

Figure 5. Test 4A80B6: $P_{\text {nom }}=1,1 \mathrm{~kW}, n_{\text {nom }}=920 \mathrm{~min}^{-1}$, idling and low load modes with reduced voltage according to the criterion of the minimum stator current (maximum power factor)

a)-for $a\left(P_{2}\right)$ and b)-for $V s, n, M, \cos \varphi, P 1(P 2)$

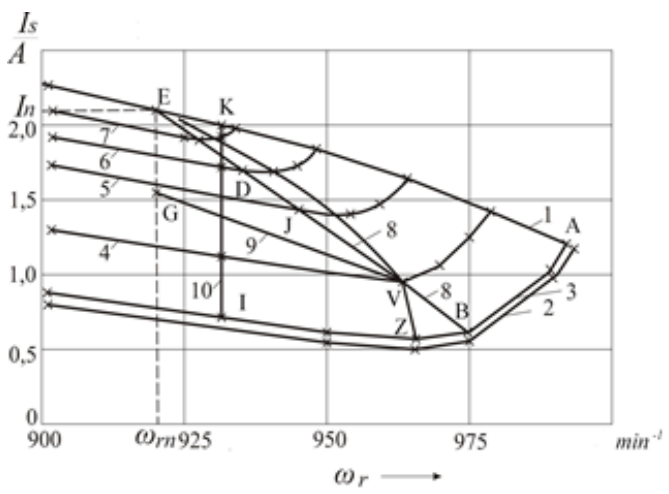

Figure 6. Electromechanical characteristics. IM 4A80B6: $P_{\text {nom }}=1,1 \mathrm{~kW}, n_{\text {nom }}=920 \mathrm{~min}^{-1}$ 
Analyzing the obtained characteristics, it can be noted that in each of them there is a minimum corresponding to the minimum value of the stator current (point B corresponds to idling; point V-to a load of 0.2 from nominal; point $\mathrm{J}$-to a load of 0.4 from nominal; point $\mathrm{D}$-to a load of 0.6 from nominal; Figure 7 shows a view of the recommended electromechanical characteristics of the suboptimal IM control system according to the criterion of the minimum stator current, where point E practically corresponds to the rated load of IM and point B is close to the optimal value for the idle. Starting from point $\mathrm{V}$ and with a further increase in load, an unstable mode of operation of the system is observed. Gradual increase in the current feedback signal (by adjusting the potentiometer R8) makes it possible to achieve stable operation, but at the same time, the amplification factor decreases, and the system continues to operate at characteristic 9 and enters the operation mode shown by point G. When a capacitor $\mathrm{C} 1$ is introduced into the feedback circuit (Key1 opens), only the alternating current feedback component is input to DA1 (Figure. 4). As shown by experimental data, the amplification factor of the system practically does not decrease. In this case, the ASCS at the initial operating mode corresponding to point B (Figure. 6), when the load increases, works on characteristic 8. By controlling the magnitude of the variable component of the current feedback, it is possible to achieve stable operation of the system in the entire range of characteristic 8 (on the segment B-E).

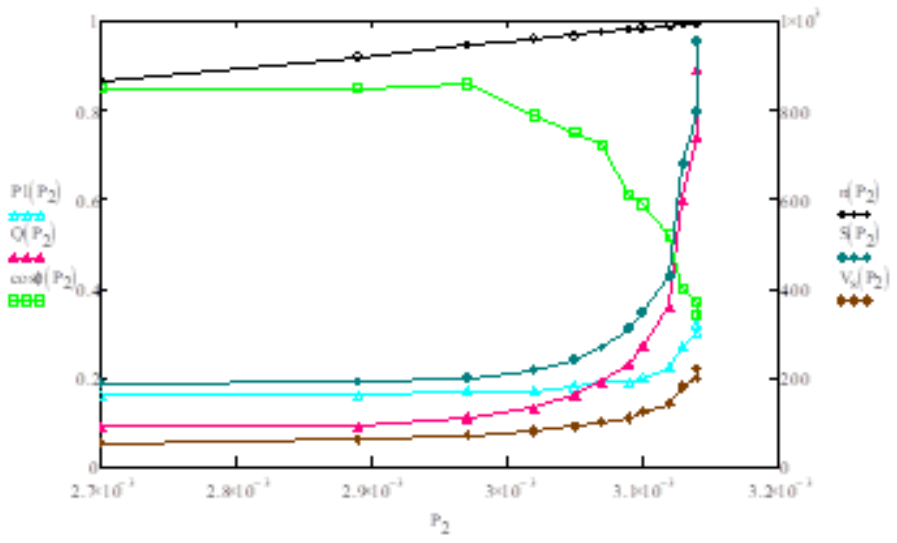

(a)

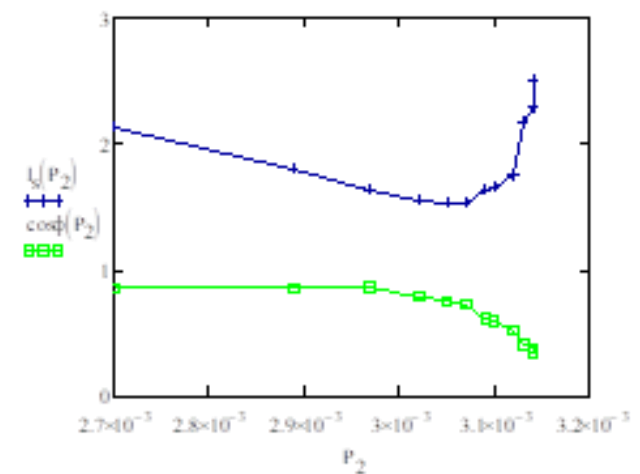

(b)

Figure 7. Test AOK2-51-6-T2: $P_{\text {nom }}=4 \mathrm{~kW}, n_{\text {nom }}=955 \mathrm{~min}^{-1}$, idle a) -for $V_{s}, Q, P_{1}, n, S\left(P_{2}\right)$ and b) -for $I_{s}, \cos \varphi\left(P_{2}\right)$

When replacing a static regulator with an astatic one (when the Key2 key is opened), the speed reference signal is selected so that IM idling works in the mode shown by point I, which corresponds to a rotational speed $w_{r}=931 \mathrm{~min}^{-1}$. With an increase in load, IM operating at characteristic 10, enters a mode close to the nominal (point K). The system works stably over the entire load range without introducing additional current feedback (potentiometer $\mathrm{R} 8$ is in the off position). The above theory and practical recommendations were tested in the training laboratory of electrical machines of SUSU on the motor AOK251-6-T2 (parameters: 220/380V, 16/10A, $4 \mathrm{~kW}, 955 \mathrm{~min}^{-1}$, efficiency 82\%, $\cos \varphi=0.78$ ). As a load, DC motor type 2PN160MUHL4 (parameters: 220V, 4.5kW, 24.2A, 1000/3000 $\mathrm{min}^{-1}$ ) was used, mechanically connected to the IM and operating in the electromagnetic brake mode. The power supply was provided by a floor-mounted induction voltage regulator (IR) type IR 59/22-U3 (parameters: 160kVA, 380V, voltage regulation limits $0-380 \mathrm{~V}$, mains current $310 \mathrm{~A}$, load current $245 \mathrm{~A}$ ). The results of the tests are placed in Table 2, Figure 7 (AOK2-51-6-T2 test: $P_{\text {nom }}=4 \mathrm{~kW}, n_{\text {nom }}=955 \mathrm{~min}-1$, idling mode), where $V_{s}-$ is the voltage on the stator; $I_{S}$-is the stator current; $P_{l}$-consumed active power; $Q$-reactive power consumption; $\cos \varphi$-is the power factor; $n$-is the rotation frequency; $P_{2}$-useful power; $S$-is total power.

The rest results of the test are placed in Table 3 and Figure 8 (AOK2-51-6-T2 test: $P_{\text {nom }}=4 \mathrm{~kW}$, $\mathrm{n}_{\text {nom }}=955$ min- 1 , the mode of small loads when the conditions of the minimum stator current and maximum power factor are satisfied). From the graphs (Figure. 7b) it can be seen that at a minimum value of the stator current, while maintaining power, the power factor $(\cos \varphi(P 2))$ varies within small limits and is approximately equal to the nominal (corresponding to the rated load). The optimized stator current linearly depends on the effective power. 
Table 2. Test AOK2-51-6-T2: $\mathrm{P}_{\text {nom }}=4 \mathrm{~kW}, \mathrm{n}_{\text {nom }}=955 \mathrm{~min}^{-1}$, idle.

\begin{tabular}{|c|c|c|c|c|c|c|c|}
\hline$V_{s}(\mathrm{~V})$ & $I_{s}(\mathrm{~A})$ & $P_{l}(\mathrm{~kW})$ & $Q$ (kWar) & $\cos \varphi$ & $n\left(\min ^{-1}\right)$ & $P_{2}(\mathrm{~W})$ & $S(\mathrm{VA})$ \\
\hline 219 & 2,5 & 0,32 & 0,89 & 0,34 & 996 & 3,14 & 951 \\
\hline 200 & 2,29 & 0,30 & 0,74 & 0,37 & 995 & 3,14 & 795 \\
\hline 180 & 2,17 & 0,27 & 0,60 & 0,40 & 994 & 3,13 & 677 \\
\hline 141 & 1,75 & 0,22 & 0,36 & 0,52 & 989 & 3,12 & 427 \\
\hline 121 & 1,65 & 0,20 & 0,27 & 0,59 & 985 & 3,10 & 345 \\
\hline 110 & 1,63 & 0,19 & 0,23 & 0,61 & 981 & 3,09 & 311 \\
\hline 100 & 1,53 & 0,19 & 0,19 & 0,72 & 975 & 3,07 & 265 \\
\hline 91 & 1,53 & 0,18 & 0,16 & 0,75 & 969 & 3,05 & 240 \\
\hline 80 & 1,55 & 0,17 & 0,13 & 0,79 & 959 & 3,02 & 215 \\
\hline 70 & 1,63 & 0,17 & 0,11 & 0,86 & 944 & 2,97 & 198 \\
\hline 60 & 1,8 & 0,16 & 0,09 & 0,85 & 919 & 2,89 & 188 \\
\hline 51 & 2,13 & 0,16 & 0,09 & 0,85 & 866 & 2,70 & 187 \\
\hline
\end{tabular}

Table 3. Test AOK2-51-6-T2 test: $P_{\text {nom }}=4 \mathrm{~kW}, n_{\text {nom }}=955 \mathrm{~min}^{-1}$, the mode of small loads when the conditions of the minimum stator current and maximum power factor are satisfied

\begin{tabular}{ccccccc}
\hline$V_{s}(\mathrm{~V})$ & $I_{s}(\mathrm{~A})$ & $M(\mathrm{Nm})$ & $n\left(\mathrm{~min}^{-1}\right)$ & $Q(\mathrm{kWar})$ & $P_{2}(\mathrm{~W})$ & \multicolumn{2}{c}{$\cos \varphi$} \\
\hline $\mathbf{9 5 , 3}$ & 1,54 & 0,01 & 970 & 0,175 & 0,196 & 0,77 \\
$\mathbf{9 4 , 7}$ & 1,80 & 0,11 & 973 & 0,18 & 0,24 & 0,813 \\
$\mathbf{9 4 , 3}$ & 1,92 & 2,0 & 955 & 0,18 & 0,26 & 0,83 \\
$\mathbf{9 3 , 6}$ & 2,21 & 3,32 & 942 & 0,19 & 0,30 & 0,84 \\
$\mathbf{9 3 , 0}$ & 2,42 & 4,22 & 931 & 0,20 & 0,34 & 0,87 \\
$\mathbf{9 2 , 5}$ & 2,82 & 6,06 & 914 & 0,21 & 0,39 & 0,86 \\
$\mathbf{9 2 , 0}$ & 2,95 & 8,17 & 906 & 0,22 & 0,41 & 0,87 \\
\hline
\end{tabular}

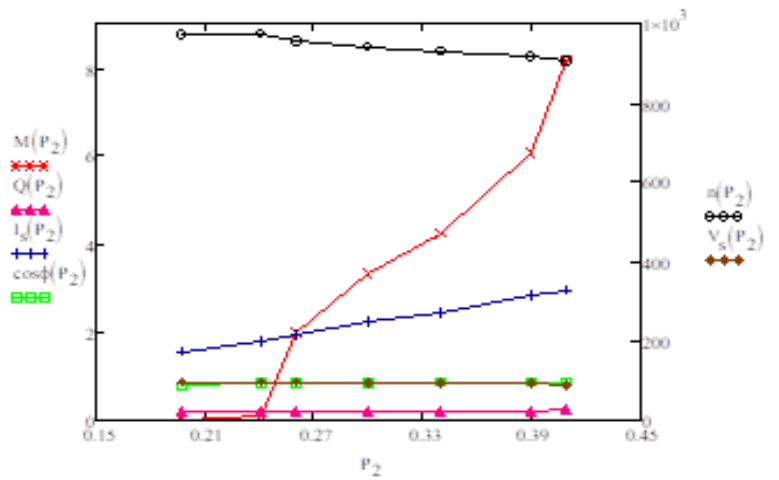

(a)

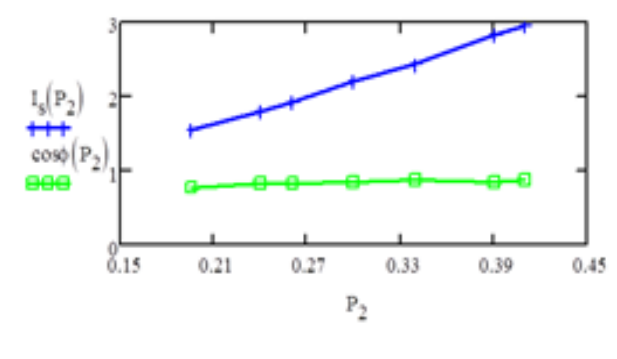

(b)

Figure 8. Test AOK2-51-6-T2 test: $P_{\text {nom }}=4 \mathrm{~kW}, n_{\text {nom }}=955 \mathrm{~min}^{-1}$, the mode of small loads when the conditions of the minimum stator current and maximum power factor are satisfied

a)-for $M, Q, I_{s}, \cos \varphi, n, V_{s}\left(P_{2}\right)$ and b)-for $I_{s}, \cos \varphi\left(P_{2}\right)$

\section{POLYNOMIAL DEPENDENCES OF THE MAIN PARAMETERS OF IM}

To determine the coefficients of polynomials approximating a given array of source points, an approximating program was written in FORTRAN. The acceptable accuracy of the polynomial description of given arrays of input data was achieved by checking the results of calculations at control points [28, 29-34]. Polynomial dependence of the second degree for the torque $\mathrm{M}$ on the speed of the motor shaft $\mathrm{n}$, the voltage of the thyristor power source Vs, the current consumed from the power source Is, the angle of control of the IPCS $a$ :

$$
\begin{aligned}
& M\left(n, V_{s}, I_{s}, a\right)=55,719 n-322,205 V_{s}+1040,842 I_{s}-376,986 a-0,008 n \times V_{s}-1,435 n \times I_{s}+0,010 n \times a+ \\
& 1,965 V s \times I_{s}+2,229 V_{s} \times a+2,694 I_{s} \times a-0,029 n \times n+0,999 V_{s} \times V_{s}-16,147 I_{s} \times I_{s}+1,241 a \times a
\end{aligned}
$$

To solve the direct and inverse control problems, the parameters of linear dependencies were determined [16]:

$$
M\left(n, V_{s}, I_{s}, a\right)=-0,0161 n+0,0964 V_{s}+1,6638 I_{s}+0,0988 a,
$$


The polynomial dependence of the power factor on the same parameters will be written as:

$\cos \varphi\left(n, V_{s}, I_{s}, a\right)=20,479 n-119,793 V_{s}+431,381 I_{s}-137,940 a+0,012 n \times V_{s}-$

$-0,638 n \times I_{s}+0,019 n \times a+1,122 V_{s} \times I_{s}+0,727 V_{s} \times a+1,401 I_{s} \times a-0,012 n \times a+$

$+0,329 V_{s} \times V_{s}-8,571 I_{s} \times I_{s}+0,401 a \times a$,

The linear approximation takes the form:

$\cos \varphi\left(n, V_{s}, I_{s}, a\right)=0,011 n-0,061 V_{s}+0,385 I_{s}-0,065 a$,

The voltage on the stator winding with stable motor operation and with minimum stator current and optimum power factor will be written as:

$V_{s}\left(n, M, I_{s}, a\right)=0,704 n+3278,201 M-7056,682 I_{s}+29,971 a-0,001 n \times n-$

$-68,340 M \times M-106,666 I_{s} \times I_{s}-0,0003 a \times a-3,417 n \times M+7,344 n \times I_{s}-$

$-0,032 n \times a+197,015 M \times I_{s}-0,355 M \times a-0,174 I_{s} \times a$,

The linear approximation takes the form:

$V_{s}\left(n, M, I_{s}, a\right)=0,163 n+1,9622 M+1,1727 I_{s}-1,0749 a$,

The current consumed from the power network for the optimum power factor will be written as:

$I_{s}\left(n, M, V_{s}, a\right)=-30,681 n-435,947 M+181,552 V_{s}+205,114 a+0,016 n \times n+3,267 M \times M-$

$-0,554 V_{s} \times V_{s}-0,6561 a \times a+0,465 n \times M-0,0030 n \times V_{s}-0,011 n \times a-0,042 M \times V_{s}-$

$-0,163 M \times a-1,206 V_{s} \times a$,

The linear approximation takes the form:

$I_{s}\left(n, M, V_{s}, a\right)=-0,0021 n+0,4147 M+0,0144 V_{s}+0,0177 a$,

\section{CONCLUSIONS}

An experimental installation was created in the laboratory of electrical engineering of SUSU and a practical version of the suboptimal IM control system was implemented according to the criterion of the minimum stator current using the example of a three-phase IM type 4A80B6. Experimental studies of the system with a static regulator have shown that it is possible to reduce the stator current of IM by $43 \%$ at Mc $=0 ; 33 \%$ with $\mathrm{Mc}=0.2 \mathrm{Mnom} ; 20 \%$ at $\mathrm{Mc}=0,4 \mathrm{Mnom} ; 9 \%$ at $\mathrm{Mc}=0,6 \mathrm{Mnom} ; 4 \%$ at $\mathrm{Mc}=0,8 \mathrm{Mnom}$ in comparison with work of an IM at the same values of the moments of loading on a natural characteristic.

A practical version was developed and a mathematical model of the suboptimal control system for IM by the criteria of the minimum stator current and the maximum power factor, operating with a constant speed reference signal with a static regulator. As IM voltage converter, TVC and IR were used. The speed reference was selected based on the condition that the stator current IM in the idle is minimized and the modes of low loads (or close to them) are satisfied [2]. The dependence of the voltage signal of the job on the main operating parameters is constructed.

The static speed controller in the experimental setup provides for load moments less than the nominal work of IM on the control characteristic, which approximates the optimal curve [2]. The evaluation of the influence of the regulating characteristic on the main parameters of IM is described by polynomials of the second and first degrees. Studies of the suboptimal control system of IM of type 4A80B6 according to the criterion of minimum stator current with an astatic regulator showed that if at the load moments $\mathrm{Mc}=0.8$ Mnom and $\mathrm{Mc}=0$, the stator currents of IM when working with the astatic and static regulators practically coincide, then for $\mathrm{Mc}=0.6 \mathrm{Mnom}$ the stator current of IM, controlled from the suboptimal system with the astatic regulator by $4 \%$, at $\mathrm{Mc}=0.4 \mathrm{Mnom}-$ by $10 \%$, at $\mathrm{Mc}=0.2 \mathrm{Mnom}-$ by $14 \%$ more than with the static regulator. As a result of the study of the nature of the electromechanical characteristics (dependence Is-n) of the operation of IM, controlled from TVC or IR, it was found that each point of the optimal curve corresponding to the minimum values of the stator current and the maximum of the power factor, at constant load moments, ranging from nominal to idle. Consequently, the linearized optimal control characteristic allows the use of a standard TVC as a static regulator [2, 26]. 


\section{REFERENCES}

[1] N. A. Sukhenko, G. Ya. Pyatibratov, A. A. Danshina, L. L. Altunyan, "Prospective Electromechanical Control Systems of Industrial Manipulator Efforts," International Journal of Power Electronics and Drive System (IJPEDS), vol. 7, no. 2, pp. 416-421, 2016.

[2] V.I. Smolin, I.G. Topol'Skaya, "Amplitude control of the moment of a three-phase asynchronous drive based on generalized energy-flow principles," Russian Electrical Engineering, vol. 85, no. 4, pp. 205-209, 2014.

[3] Abdel-Halim, I. A. M., Al-Ahmar, M. A., Elfaraskoury, M. E., \& Mahmoud, E. M., "A novel approach for the analysis of a thyristor-controlled induction motor," Journal of Electrical Engineering, vol.15, no. 2, pp. 101-112, 2015.

[4] Petrushin, V. S., Yakimets, A. M., Plotkin, Y. R., \& Yenoktaiev, R. N., "Investigation of the smooth start-up of an induction motor," Technical Electrodynamics, no.1, pp. 56-61, 2018.

[5] Petrushin, V., R. Yenoktaiev, and J. Plotkin, "Comparative Analysis of Methods for Starting Squirrel-Cage Induction Motors," 2016.

[6] Chuang, H. G. Li, and C. Lee. "The Efficiency Improvement of AC Induction Motor with Constant Frequency Technology." Energy, vol. 174, pp. 805-813, 2019.

[7] Ilinski, N. "Frequency Converters in Water Supply Systems for Energy Saving." Energy Engineering: Journal of the Association of Energy Engineering, vol. 97, no. 5, pp. 7-20, 2000.

[8] Ilinski, N. F., "New approach to AC motor selection and checking," Paper presented at the IEE Conference Publication, no. 412, pp. 32-36.

[9] V L Kodkin, A S Anikin, A A Baldenkov, "The analysis of the quality of the frequency control of induction motor carried out on the basis of the processes in the rotor circuit," Journal of Physics: Conference Series, vol. 944,

[10] Mallard, V., Parent, G. Demian, C. Brudny, J.-F., Delamotte A., "Increasing the Energy Efficiency of Induction Machines by the Use of Grain-Oriented Magnetic Materials and Die Casting Copper Squirrel Cage in the Rotor," IEEE Transactions on Industry Applications, vol. 55, no. 2, pp. 1280-1289, 2019.

[11] Vladimir L. Kodkin, Alexandr S. Anikin and Alexandr A. Baldenkov, "Nonlinear Dynamics of Asynchronous Electric Drive: Engineering Interpretation and Correction Techniques", Control Theory in Engineering. IntechOpen, 2019.

[12] Kodkin V.L., A.S. Anikin, A., Baldenkov, "Analysis of stability of electric drives as non-linear systems according to Popov criterion adjusted to amplitude and phase frequency characteristics of its elements," 2nd International Conference on Applied Mathematics, Simulation, and Modeling AMSM, 2017.

[13] Ferreira, F.J.T.E. De Almeida, A.T., "Overview on energy saving opportunities in electric motor driven systems Part 1: System efficiency improvement," 52nd IEEE/IAS Industrial and Commercial Power Systems Technical Conference, I and CPS, 2016.

[14] Ferreira, F.J.T.E. De Almeida, A.T, "Overview on energy saving opportunities in electric motor driven systems Part 2: Regeneration and output power reduction," 52nd IEEE/IAS Industrial and Commercial Power Systems Technical Conference, I and CPS, 2016.

[15] Donolo, P.D., Pezzani, C.M., Bossio, G.R., De Angelo, C.H., Donolo, M.A., "Derating of induction motors due to power quality issues considering the motor efficiency class," IEEE Transactions on Industry Applications, vol. 56, no. 2, pp. 961-969, 2020

[16] Giraldo, E., Ruschetti, C. Verucchi, C. Bossio, G. Bossio, J., "Alternative approach to improving efficiency level in small induction motors," IEEE Latin America Transactions, vol. 16, no. 8, pp. 2138-2144, 2018

[17] Kodkin, V.L, A. S. Anikin, A. A. Baldenkov, "Structural correction of nonlinear dynamics of frequency-controlled induction motor drives," International Journal of Power Electronics and Drive Systems, vol. 11, no. 1, pp. 220-227, 2020.

[18] Loday-Richaud M., "Divergent Series, Summability and Resurgence II. Simple and Multiple Summability," Springer International Publishing, no. 272, 2016.

[19] Gun V.S., Bakin A.A., Litvinova E.V., "Analysis of the dynamic properties of the discrete control of the regulation by the linear approximation of difference equations," Science SUSU: proceedings of the 70th scientific conference. Technical Science Section, 2017.

[20] Gun V.S., Bakin A.A., Litvinova E.V., "A way of the ac machine stator current decreasing," Science SUSU: proceedings of the 70th scientific conference. Technical Science Section, 2017.

[21] Kodkin, V.L, A.S. Anikin, A.A. Baldenkov, "Stabilization of the stator and rotor flux linkage of the induction motor in the asynchronous electric drives with frequency regulation," International Journal of Power Electronics and Drive Systems, vol. 11, no. 1, pp. 213-219, 2020.

[22] Yang, G., Zhang, S., Zhang, C., Yang, Y., "Principle analysis of torque ripple test bench for electric machine for electric vehicle application," Proceeding 2019 5th International Conference on Energy Materials and Environment Engineering, ICEMEE 2019; Kuala Lumpur; Malaysia, vol. 295, no. 5, 2019.

[23] Tapia Montero, M.A, Hoffer Garces, A.E. Tapia Ladino, J.A. Wallace Collao, R.R., "Simulation and Analysis of an Axial Flux Induction Machine," IEEE Latin America Transactions, vol. 15, no. 7, pp. 1263-1269, 2017.

[24] Kodkin, V.L, A.S. Anikin, A.A. Baldenkov, "Performance identification of the asynchronous electric drives by the spectrum of rotor currents," International Journal of Power Electronics and Drive Systems, vol. 10, no. 1, pp. 211-218, 2019.

[25] Gnacinski, P. Tarasiuk, T., "Energy-efficient operation of induction motors and power quality standards," Electric Power Systems Research, vol. 135, no. 1, pp. 10-17, 2016. 
[26] Gun V.S., Bakin A.A., Sidorenko N.Yu., "A mathematical model of an asynchronous motor speed control system to increase its life," Proceedings of the IV International Conference "Safety Problems of Critical Building Infrastructures-SAFETY, 2018.

[27] Trianni, A. Cagno, E. Accordini, D., "Energy efficiency measures in electric motors systems: A novel classification highlighting specific implications in their adoption," Applied Energy, vol. 252, no. 113481, 2019.

[28] Kodkin, V.L, A.S. Anikin, A.A. Baldenkov, "The dynamics identification of asynchronous electric drives via frequency response," International Journal of Power Electronics and Drive Systems, vol. 10, no. 1, pp. 66-73, 2019.

[29] Pliugin, V. Shilkova, L. Lettl, J., Buhr, K., Fajtl, R., "Analysis of the electromagnetic field of electric machines based on object-oriented design principles," Proceeding Progress in Electromagnetics Research Symposium, vol. 2015, pp. 2522-2527, 2015.

[30] Kvashnin V.O., Cherednik Yu.N., "Construction of a mathematical model of an induction motor in synchronous axes with temperature compensation for changes in rotor flux linkage," Electrotechnical and Computer Systems, vol. 3, no. 79, pp. 256-257, 2011.

[31] Donolo, P.D. Pezzani, C.M. Bossio, G.R., De Angelo, C.H., Donolo, M.A., "Derating of induction motors due to power quality issues considering the motor efficiency class," IEEE Transactions on Industry Applications, vol. 56 no. 2, pp. 961-969, 2019.

[32] Gladyshev, S., Gladychev, N., Goun, V., and Bakin, A., "Line Voltage Control of Induction Motor for Increase Its Efficiency in Stable Area," SAE Technical Paper 2018-01-1830, 2018.

[33] Bakin A.A., Gun V.S., Sidorenko N.Yu., "Experimental determination of suboptimal parameters for controlling an induction motor by the criterion of minimum current," Science SUSU: proceedings of the 70th scientific conference. Technical Science Section, 2018.

[34] Santos, V.S. Felipe, P.R.V. Sarduy, J.R.G., Lemozy, N.A., Jurado, A., Quispe, E.C., "Procedure for determining induction motor efficiency working under distorted grid voltages," IEEE Transactions on Energy Conversion, vol. 30, no. 1, pp. 331-339, 2015. 